\title{
El sistema oral acusatorio en Colombia: Reforma y habitus jurídico*
}

\author{
Álvaro Moreno Durán. Ph.D*** \\ Recibido: 19 de Septiembre de 2013 • Revisado: 8 de octubre de 2013 \\ - Aprobado: 20 de octubre de 2013 \\ Las estructuras jurídico administrativas son construidas \\ al mismo tiempo que los cuerpos de los juristas, bajo la \\ forma de un contrato entre los cuerpos de los juristas que se \\ constituyen como tal y controlan rigurosamente su propia \\ reproducción, y el Estado. \\ Pierre Bourdieu
}

\section{Resumen}

El presente artículo es el resultado de una investigación en curso de la facultad de Derecho de la Universidad Santo Tomas de Bogotá, que pretende estudiar los comportamientos de los "agentes" al verse enfrentados al sistema innovador penal acusatorio.

La teoría de los campos de Bourdieu es el punto de partida de la investigación para determinar los aspectos de la sociología jurídica que repercuten en el habitus de los agentes intervinientes en los litigios. De esta manera el análisis sobre sistema penal acusatorio y habitus jurídico determinará las variables que resultan, para las partes, más difíciles de asimilar y aquellas que se apropian fácilmente.

El resultado de la investigación será un apoyo para las discusiones académicas sobre el tema, en pro de coadyuvar al sistema a establecer los objetivos propuestos no

"Artículo de investigación dentro del proyecto denominado Reforma al Sistema Penal colombiano: Acto legislativo 03 de 2002, y Habitus Jurídico.

** Docente-investigador de la Universidad Santo Tomás. Grupo de investigación Derecho y sociedad. Correo electrónico: moreno_alvaro@hotmail.com 
cumplidos y las estrategias de mejoramiento para un litigio más eficaz y un proceso que garantice a cabalidad los derechos fundamentales.

Palabras clave: Habitus, Sistema penal Acusatorio, comportamiento, sociología jurídica, habitus jurídico, proceso, derecho, economía, política.

\title{
The Accusatory System in Colombia: CHANGES AND LEGAL HABITUS
}

\begin{abstract}
This article is the result of an ongoing investigation that takes place at the Faculty of Law at Santo Tomas University in Bogotá, and what the group aims to study is the behavior of the "agents" due to the innovation of legislation who gets involved the Colombian penal system.

The theory Bourdieu fields is the starting point of the investigation to determine the aspects of legal sociology that affect the habitus of the agents involved in litigation. Therefore research on adversarial criminal justice system and legal habitus determine the variables that are more difficult to assimilate to the parties and those who appropriate easily. The result of the research will be an academic support in discussions on the issue in favor of contributing the system to establish unfulfilled objectives and breeding strategies for most effective litigation and a process that guarantees fundamental rights fully.
\end{abstract}

Keywords: habitus, accusatory penal system, behavior, sociology of law, legal habitus, process, law, economy, policy.

\section{Sistema de contraditório na Colômbia: REFORMA E HABITUS LEGAL.}

\section{Resumo}

Este artigo é o resultado de uma investigação em curso que está sendo realizado na Faculdade de Direito da Universidade de Santo Tomas e Bogotá tem como objetivo estudar o comportamento dos "agentes" para ser confrontado com o inovador acusatório. A teoria do campo de Bourdieu é o ponto de partida da investigação para determinar os aspectos da sociologia do direito que afeta o habitus dos agentes em litígio 
partida. Assim, a investigação sobre o sistema de contraditório e determinar as variáveis habitus legais que são mais difíceis de digerir para os partidos e aqueles que são facilmente apropriados.

O resultado da pesquisa será um apoio para as discussões acadêmicas sobre a questão em favor do sistema de contribuir para o estabelecimento das metas não cumpridas propostas e estratégias de melhoria para uma disputa mais eficaz e um processo que garanta os direitos fundamentais totalmente.

Palavras-chave: habitus, comportamento contraditório, sociologia do direito, habitus processo legal, direito, economia, política, sistema penal.

\section{Introducción}

El presente documento se ubica temporalmente entre la aparición del acto legislativo 03 de 2002 al 2013 en Colombia y se realiza mediante un análisis documental general y una observación empírica de cien procesos jurídicos en Bogotá.

El tema alude a las contradicciones que el nuevo sistema oral acusatorio presenta, supuestamente, en cuanto a las prácticas, las estructuras y los factores de su dinámica. Los cambios que presenta la innovación del sistema acusatorio traen consigo resistencias, inadaptaciones, adaptaciones, nuevos estilos de trabajo, y por ende, nuevas maneras de comprensión y de asimilación. Que en el "Habitus" del operador se manifestará de alguna manera. La discusión teórica y práctica de este concepto se propone con el objeto de hallar indicadores que determinen los elementos de cambio (en los operadores).

Con base en la teoría del campo jurídico y el habitus jurídico y los de concepto acusatorio y de oralidad, se propone una construcción de interrelaciones teóricas que nos permita observar el fenómeno en cuestión.

Desde esta perspectiva socio jurídica las prácticas y los razonamientos jurídicos son el discurso de un "campo"; el derecho es entonces, desde su enunciación hasta su interpretación y aplicación, una práctica social, teniendo en cuenta que el campo es una estructura externa con particularidades especiales como límites, lenguaje, codificación, los agentes que interactúan y por supuesto, la relación y contradicciones que dentro de ese lugar se suscitan por el poder de un capital específico, en este caso del capital jurídico (Moreno y Ramírez, 2011). 
Esta definición nos permite adecuar nuestro tópico, que tiene establecidas dichas singularidades, dentro del campo jurídico; uno de los aspectos que vamos a observar es el del lenguaje: ir de lo escrito a lo oral; además de ciertos ritos, como la disposición de los agentes en un espacio singular, en los que se ejercen las prácticas del nuevo sistema; y el contraste entre los elementos clásicos y los innovados que nos permitirá observar las resistencias y los mecanismos o estrategias de adaptación.

El habitus jurídico es otro de los conceptos que hace parte de nuestras herramientas teóricas. Es una estructura interna del individuo que ha interiorizado las disposiciones sociales como normas y conductas que regulan su contexto, a partir del papel del derecho. Este habitus aplicaría, desde la teoría, sobre nuestros objetos de investigación, con los operadores jurídicos para obtener los indicadores de las costumbres interiorizadas en los sistemas clásicos y las nuevas disposiciones con base en el sistema innovador. Estas costumbres o habitus jurídicos que se manifiestan ya en conductas, serían una de las maneras de determinar cuáles son los impactos o cuáles los conflictos que causarían estas nuevas prácticas jurídicas a través del sistema oral acusatorio.

Acerca de los alcances de la investigación se espera que contribuya al debate teórico en el continente para el aporte al sistema jurídico latinoamericano desde lo teórico-práctico para construir herramientas que contribuyan al perfeccionamiento del sistema; y a la academia, para generar conocimiento de trabajos comparativos de este orden con el objeto de proponer desde ellas tendencias generales.

Desde el punto de vista de Ferrari (citado por Flórez, 2010), el objeto de investigación nos permite observar la reforma del sistema de enjuiciamiento penal como una acción social, dicho de otra manera, la sociología jurídica o la sociología del derecho

enfrenta su objeto -el derecho- desde una perspectiva diferente respecto de la del jurista comprometido en el análisis y en la aplicación del derecho positivo, del “jurista positivo" (...), podemos afirmar en efecto que el derecho es asumido por el jurista positivo como un elemento constante, el presupuesto y horizonte de su acción. Por el contrario, para el sociólogo el derecho aparece como una variable, que se debe considerar y medir con relación en otras variables que influyen en la acción humana. 
La anterior afirmación del autor italiano nos permite pensar que el sujeto que pretendemos examinar desde la sociología jurídica es una variable del derecho con relación a otras variables, en este caso, del mismo derecho; que en su conjunto se supone, ejerce una movilidad social al interior de la estructura como en algunos impactos que puede ocasionar hacía los aspectos sociales en general. De tal manera, solo el análisis de la perspectiva de los cambios que sugiere el nuevo sistema es lo que se pretende observar con la idea de determinar ciertas perspectivas, que sin duda podría aportar al conocimiento del derecho desde el analisis sociológico para poder observar su dinámica.

Ante estas eventualidades, desde la sociología jurídica se propuso adelantar la investigación con el objeto de encontrar indicadores que determinen los elementos de cambio -en los operadores-. Para ello abordamos, desde los puntos de vista metodológico y teórico, los fundamentos de campo y de habitus jurídico como concepciones de las ciencias sociales y del derecho.

En cuanto a la pertinencia de esta investigación puede afirmarse que surgió de la necesidad de que las ciencias jurídicas den cuenta de la puesta en práctica de estas políticas de la reforma para analizar las tendencias de sus impactos, su validez y su legitimidad desde y a partir de los operadores. Estudios que en nuestras investigaciones del estado del arte no se han realizado hasta ahora en Colombia.

La ponencia además de esta introducción tiene una tesis central coherente con el problema de la investigación; primero se habla de los antecedentes históricos del Sistema Penal Oral Acusatorio, luego de los móviles del Sistema en Colombia y su importación, y por último se expone una síntesis de la investigación en la Universidad Santo Tomás y algunas conclusiones.

\section{Tesis central}

Los principios que suponen las dinámicas del campo jurídico en Colombia en el último decenio mediante la implementación del Sistema Oral Penal Acusatorio en Colombia; cuya herramienta fundamental es el juicio oral que tiene como objetivo "materializar los principios y valores procesales tales como los de publicidad, concentración, contradicción, inmediación, igualdad, lealtad, buena fe y dignidad humana"; son quizá, la garantía para hallar la eficacia y la legitimidad de dicho sistema. Y para tal efecto es necesario, trascender la reforma normativa hasta llegar a los dispositivos interiorizados de los operadores del derecho o 
habitus jurídicos, traducidos en la creación de nuevos valores procesales éticos, que identifiquen a los profesionales del derecho con una verdadera vocación humana y social. Con base en esta presunción se pretende identificar la tensión que en las prácticas jurídicas se puedan presentar entre los valores culturales arraigados en los tradicionales y las paradigmáticas formas de enjuiciamiento inquisitivo, y las nuevas formas adversariales del sistema en vigencia, basado en lo retórico y dialéctico del razonamiento oral.

\section{Antecedentes históricos del Sistema Oral Penal Acusatorio}

Antes señalamos como inquisitorial el sistema donde el juez adquiere poderes prácticamente ilimitados, y la forma escrita y la reserva predominan; en este tipo de práctica, la investigación y el juzgamiento las realiza un único funcionario, y la prueba no es conocida por el juez de forma directa sino a través de la fiscalía (la mayoría de las veces) que la presenta en forma de expediente, es decir, el funcionario de la rama judicial solo conoce lo que un tercero le describe sobre la práctica de la prueba, mediante un documento que no va más allá de la mera descripción fáctica y la defensa poca importancia tiene porque todo el protagonismo lo adquiere el inquisidor. Así, este sistema se caracteriza por la permanencia de la prueba, lo que hace que la etapa del juicio sea un simple rito procesal para cumplir con una etapa y pasar a emitir la sentencia respectiva.

Por el contrario, se afirma que cuando nos referimos al sistema acusatorio se habla de uno garantista y respetuoso de los derechos humanos. Por tales razones se supone que es un sistema liberal y democrático como resultado de las luchas sociales. En el que existe una separación de funciones, es decir, la acusación, que adquiere gran importancia, la cumple un funcionario distinto al juez, por ello se habla de que en el sistema penal acusatorio el juez tiene neutralidad, lo cual supone que la oficiosidad es una excepción que casi nunca se presenta. Otra diferencia es que este se basa en la oralidad, la publicidad y la contradicción probatoria. La oralidad, a la vez que se constituye en fundamento del sistema, es parte del debido proceso en la formación de la prueba, es decir, la prueba se practica oralmente en audiencia pública y con las garantías inherentes a todos los intervinientes. 
Después de estas aclaraciones con relación a los dos tipos de sistemas veamos la procedencia o su génesis en el derecho norteamericano.

Con el arribo de los ingleses a Norteamérica, llega la incorporación de la tradición jurídica anglosajona. Esa tradición destaca la figura de la víctima en torno al derecho penal, y tuvo gran influencia para el ordenamiento penal y procesal en lo que iba a constituirse el campo jurídico en los Estados Unidos. De tal suerte que la persecución fue la regla heredada del sistema inglés, y el papel que ocupó la víctima como principal personaje entorno al derecho penal hasta principios del siglo XVIII.

Alexis de Tocqueville (1996) explica en su obra La democracia en América, cómo desde el carácter de los primeros colonos, aunque diversos, los unió la lengua y unos principios morales y políticos definidos desde antes de dejar la vieja Europa. Y eran el gobierno municipal y la soberanía del pueblo; el germen del puritanismo inglés y el espíritu ascético que no buscaba riquezas si no la libertad para vivir a su manera.

Para Tocqueville, lo que impulsó a los americanos, desde entonces, fue el deseo de igualdad y no tanto el de libertad, por tanto tuvieron las mismas posibilidades de poseer un gobierno de soberanía popular como uno absolutista, aunque las circunstancias los llevasen al primero. A través de los años las costumbres y las prácticas sociales construyeron un habitus colectivo y un Ethos que fundamentaban la vida cotidiana, sus normas, reglas y conductas traducidas en sus sistemas jurídicos a lo largo de su historia. Es esa fijación por la libertad individual y a su vez por la igual es la que hace que se teja según Tocqueville, la urdimbre de la democracia en Norteamérica.

Con base en este referente histórico, tanto el sistema como sus operadores jurídicos, son aceptados por el pueblo y legitimados por los mismos mediante el reconocimiento de quienes encarnan ese habitus colectivo y sentimientos que van más allá de las normas escritas, de ahí que por ejemplo un juez, tiene que ser alguien reconocido como un portador de valores éticos y morales, lo que asegura en el imaginario de sus conciudadanos la neutralidad y la sabiduría para tomar sus decisiones, con base en los casos excepcionales de infracciones o delitos individuales sin afectar los principios generales. Por eso sus procesos de basan en casos particulares y estos son expuestos adversarial y públicamente.

Tocqueville también señala que la mayor dificultad de trasplantar el sistema norteamericano a Europa era la falta de principios comunes. En Norteamérica 
la constitución permanece estable porque está compuesta por principios fundamentales inamovibles, que se presumen son aceptados e interiorizados por todos los ciudadanos, los cambios en la normatividad para cada caso concreto o nueva situación se estipulan en normas de menor jerarquía. Por el contrario el panorama legislativo europeo no contaba con un marco común o una base de principios sobre los que las demás normas debían construirse o transformarse, lo que deja al conjunto normativo sin límites.

Con estos argumentos, sucintamente señalados, se puede plantear ¿Cómo el sistema penal oral acusatorio proveniente de Norteamérica se puede adaptar o ajustar a sociedades como la nuestra, cuyas estructuras sociales se basan en habitus $\mathrm{y}$ valores tan diferentes y vulnerables?

\section{Móviles del Sistema en Colombia y su importación}

Antes de la constitución de 1991 el Presidente de la República en ejercicio de las facultades extraordinarias conferidas por el Congreso, expidió el nuevo Código Penal que pretendía hacer reformas. Tal fue el caso de la reforma carcelaria, cuya congestión desbordaba la infraestructura en el país y por entonces se comenzó hablar de "libertad condicional".

Desde la Asamblea Nacional Constituyente (Carrillo, 1991), se estableció la idea de cambiar el sistema procesal penal con carácter inquisitivo a uno acusatorio, cuyos móviles a la transformación se argumentaban por la ineficiencia, impunidad y falta de garantías en materia de derechos fundamentales.

De acuerdo con las discusiones de entonces los siguientes principios se pusieron en la mesa de discusión (Londoño, 1991):

1. Independencia de la Fiscalía General de la Nación respecto del ejecutivo.

2. Monopolio de las funciones de investigación y acusación en cabeza del Fiscal General de la Nación y sus agentes.

3. Establecimiento de un procedimiento único para la investigación y el juzgamiento de delitos.

4. Igualdad de condiciones entre el ente acusador y la defensa durante todas las etapas del proceso. 
Dichos principios fueron planteados por subcomisiones, propuesta que sugirió la Fiscalía junto con un sistema mixto de corte acusatorio. Es decir, continúo el sistema penal inquisitorio.

\section{Móvil político: Las reformas de los sistemas jurídicos en la era neoliberal}

El neoliberalismo se considera una ideología fuerte, sin fundamentos científicos, no solo en economía, también se fundamenta en geopolítica y biopolítica; como lo advirtiera el economista ecuatoriano Pablo Dávalos (s.f): "debe ser visualizado como la compleja búsqueda de los centros del poder, por sistematizar, legitimar y racionalizar la regulación del sistema mundo en una fase particular, aquella de la preeminencia del poder financiero mundial".

Asimismo, Dávalos (s. f.),

Entiende por regulación del sistema-mundo capitalista las formas por las cuales el capitalismo busca su propia re-producción, esto es, la forma por la cual el propio sistema crea y re-crea las condiciones históricas que le son propicias para su existencia en términos de tiempo y espacio.

Interpretando a este autor, se puede advertir que en la política, el neoliberalismo propicia los fundamentos del Estado moderno, la democracia, y el sistema político moderno, desde el liberalismo clásico. En ética, crea los principios de la convivencia social desde una posición determinada por la razón de mercado y el individualismo. En historia fundamenta la razón de mercado como heurística y hermenéutica de la misma. Y en jurídica establece un modelo de Estado y de contrato social desde el cual se regula y administran las sociedades.

Por lo anterior se puede deducir que el Estado social de derecho tiene sus orígenes en la ideología neoliberal expresada como nicho para sus intereses y su proyecto político.

De acuerdo a Dávalos (s. f.) la noción Estado social de derecho

se distancia de la concepción tradicional del liberalismo que consideraba al derecho como un formato que se adecua a las necesidades del mercado y del capitalismo desde fuera de la economía, y las sanciona desde una posición separada de la lógica 
de los mercados. Para el liberalismo clásico, la esfera del derecho era parte de la esfera política que se justificaba desde la noción básica del Estado de naturaleza, mientras que la economía era parte de la sociedad civil. Derecho y economía, en el liberalismo clásico, tenían una misma raíz pero caminos separados. Por el contrario, para los neoliberales, el derecho no es un formato que se adecue al mercado, sino que expresa las reglas de juego del sistema. Esta distinción de reglas de juego es fundamental y es parte de la tradición del derecho consuetudinario del derecho anglosajón. Ahora bien, estas reglas de juego para el funcionamiento del capitalismo no vienen desde fuera de las sociedades, sino que por el contrario las constituyen.

De acuerdo a lo expresado se deduce que, el Estado tiene como papel garantizar el respeto a las reglas de juego del mercado, y de la mano de este, le asegura el libre desarrollo de sus mecanismos y el arreglo de sus fines.

\section{Móvil económico}

Lo referido nos permite hacer la conexión con lo sucedido en materia de política y derecho en Colombia. Después de que el país ingresó a la Organización Mundial del Comercio (OMC) adoptó los principios del modelo económico y político neoliberal. Desde entonces el Estado se minimiza, tiene una mayor participación en el sector privado en la economía y en la defensa de la libertad individual. Fortaleció la protección de los contratos civiles por medio de la legislación comercial, y en términos generales, ofreció una seguridad jurídica para las actividades relacionados con el comercio y la economía.

Con la implementación de la apertura económica Colombia expidió varias leyes con el objetivo de desmantelar las principales instituciones de bienestar, con el discurso de proteger al sistema económico de efectos considerados como autodestructivos e ineficientes. De ahí que se implementaron entre otras, la reforma laboral de 1990 y la reforma a la salud y a la seguridad social de 1993.

Hoy cuando se habla del Sistema Oral Penal Acusatorio, se piensa, en primer lugar, en el marco neoliberal señalado, en donde surge y sus móviles políticos y económico; cuya tendencia se puede señalar en varios países de América Latina. Posiblemente con objetivos como la simplificación del tiempo en los procesos, el ahorro económico en la inversión de los mismos por parte de los Estados y la simplificación de las infraestructuras, entre otros principios próximos al utilitarismo y pragmatismo anglosajón, con el agregado de que la racionalidad y la planificación del sistema asegurarían más pecunio para que estos cumplieran con 
los compromisos adquiridos en los empréstitos, y el mundo de los mercados fluya con el nuevo laissez paseé y laissez faire empujados por la mano invisible del egoísmo y la competencia pura.

\section{Móvil jurídico}

De acuerdo al balance de los primeros cinco años de funcionamiento del Sistema Penal Acusatorio en Colombia, realizado en el 2011 por la Corporación Excelencia en la Justicia se puede afirmar que los objetivos que motivaron la reforma fueron: hacer más eficiente el sistema penal; perseguir la criminalidad grave y organizada, según lo político criminal vigente; hacer más garantista el sistema penal; garantizar idónea atención a víctimas; implementar el programa de justicia restaurativa; mejorar la confianza en el sistema penal y mejorar la calidad de las decisiones en materia penal.

De acuerdo con el estudio en mención, el Sistema Penal Acusatorio aún es débily en algunos aspectos y lugares, deficiente. Lo que significa que deben investigarse los factores que hacen al sistema poco eficaz y eficiente. De ahí la inquietud académica que nos ocupa de averiguar quizá por elementos de fondo como las disposiciones culturales y comportamentales de los operadores con relación al sistema, a la luz del concepto de habitus jurídico.

\section{Desarrollo de la investigación en la Universidad Santo Tomás}

La oralidad y lo acusatorio constituyen categorías de análisis de investigación pues con ellas se busca demostrar si los agentes intervinientes en el sistema de enjuiciamiento penal incluyen o no estos elementos; y la medida en que constituyen o no habitus jurídico.

En relación a las investigaciones con esta óptica, Cuellar (en Moreno y Fortich, 2013) advierte en el caso que se cita de la autonomía del campo jurídico que:

La reproducción de estas órdenes de acción se encuentra a manera de disposición incorporada en los habitus de los diversos agentes que son parte legítima de la construcción y la puesta en práctica de las leyes que se producen en el seno y bajo la lógica de acción de un campo jurídico concreto. Sin embargo, la autonomía de este campo en cuanto su operatividad práctica, no se encuentra aislado de intereses de tipo económico o político que condicionan de manera subjetiva los intereses de los agentes que, en términos ideales, deberían actuar bajo la lógica pura del derecho 
formal. Es precisamente la interiorización de las reglas prácticas del juego judicial, sustentado en principios de la teoría pura del derecho, la lógica que condiciona a actuar a los agentes del campo jurídico en relación a intereses que no tienen que ver con la consecución del capital específico en juego (en este caso el capital jurídico y lo que sus implicaciones simbólicas conlleve).

Si bien, una de las categorías de análisis de la investigación es la oralidad, la entendemos para el objeto de nuestro estudio como una de las características propias del sistema acusatorio; condición que en la Teoría del Campo Jurídico puede resultar de mayor reto para los agentes que intervienen en el proceso; así, enmarcamos la oralidad como una variable de estudio que comprenderá el todo del habitus jurídico detentado por las personas durante las diferentes etapas procesales.

Por una parte la oralidad se fundamenta en que todas las peticiones formuladas por las partes al funcionario judicial, se basarán y decidirán de forma oral, en audiencia y con la intervención de las partes.

La actuación procesal será oral, en su realización se utilizarán los medios técnicos disponibles que permitan imprimirle mayor agilidad y fidelidad; la oralidad es una variable del Sistema penal Acusatorio.

La investigación está dirigida a utilizar un lenguaje apropiado, de acuerdo a conceptos socio-jurídicos basados en el habitus y el lenguaje simbólico, y usado por los actores del proceso oral, ya sea en el sistema penal acusatorio u otro, siempre y cuando tenga por objeto analizar como variables la oralidad y lo acusatorio y a su vez interpretarlos, a partir de la teoría de Pierre Bourdieu, del habitus, para estudiar las diferentes audiencias, la intervención de las partes en un proceso determinado y su comportamiento ante situaciones concretas, en el entendido de que los actores de dicho proceso emplean el lenguaje, las miradas, la expresión corporal, las imágenes, medios de apoyo audiovisual, y la capacidad de adquirir la atención del público; en sí, entender los argumentos y razones que se usan para convencer o persuadir de alguna posición al receptor.

La oralidad analizada dentro del campo socio-jurídico, sus elementos y componentes; además resolveremos las contrariedades del sistema oral, el cual se desenvuelve a través de prácticas, estructuras y factores propias de su dinámica; indicadores que también serán estudiados dentro del proyecto, para lograr un resultado acerca de las formas propias de los procesos orales, el papel de las partes, sus intervenciones, el lenguaje corporal y simbólico, y que se obtendrán mediante la observación 
etnográfica, como método de investigación, lo cual nos proporcionará, los indicios para determinar las tendencias de adaptación o desadaptación del sistema oral.

La oralidad, además de estar vinculada al principio de publicidad, variable que también será analizada en nuestra investigación; representa la principal garantía del proceso penal, pero dicho instrumento, para Ferrajoli (citado en Morales y Martínez, 2011) según enseñanzas de Chiovenda y Calamandrei su valor

\begin{abstract}
Reside esencialmente en sus corolarios de la inmediación y concentración del juicio, que precisamente la separación en dos las fases del proceso mixto hace imposible. La oralidad, en efecto, solo vale para garantizar la autenticidad de las pruebas y el control del público y del imputado sobre su formación si comporta, en primer lugar, el tratamiento de la causa en una sola audiencia o en varias audiencias próximas, y por tanto sin solución o continuidad, en segundo la identidad de las partes intervinientes del proceso, de los jueces desde el inicio de la causa hasta la decisión en tercer lugar el dialogo y lenguaje utilizado entre las partes y el juez para que este conozca la causa no a base de escritos muertos, sino base de la impresión recibida.
\end{abstract}

Por su parte Granados (citado en Morales y Martínez, 2011) enseña que la oralidad es vista al menos en dos formas: el aspecto puramente escénico y el contenido contradictorio del mismo, es decir, un debate oral, y es necesario que se trabe un debate entre el defensor y el ente que acusa.

La oralidad es el principal cambio que sufre el trámite procesal, ya sea en el Sistema Penal tras la reforma del 2002, el proceso laboral, civil, o cualquier otro, lo que implica que los jueces deben adoptar decisiones en el juicio oral que permitirán dar una perspectiva y visión diferentes acerca del proceso.

En la Teoría del Campo Jurídico, se analizará simplemente la oralidad y lo acusatorio como variables, sin que ello signifique, que son componentes únicos en la investigación, pues encontramos otras variables (eficacia del proceso, impunidad, errores procesales, mecanismos alternativos de solución de conflictos (MASC), entre otras), para lograr enmarcarnos en el habitus jurídico de los actores procesales.

Debido al cambio profundo de paradigmas en la cultura jurídica del país en la que habrá que conocer nuevos estilos en la litigación, y en la negociación penal, la oralidad viene a convertirse en una nueva forma o estrategia de litigación que requiere desarrollar destrezas y técnicas para un proceso más ágil; un método que busca que en los procesos todas las partes argumenten oralmente en las distintas 
audiencias, ante jueces y magistrados, toda situación jurídica o fáctica. La forma verbal es una estructura metodológica nueva que facilita el trabajo de los litigantes.

La interacción de los sistemas jurídicos y el intercambio continuo entre estos y el derecho comunitario, conllevan a procesos de importación y exportación de derecho, a trasplantes jurídicos que generan destrucción o trasformación del derecho de las comunidades indígenas que habitaban en la región y la construcción de los ordenamientos jurídicos de las colonias, así por ejemplo el Código Civil Chileno, redactado por Andrés Bello, fue influenciado por el Código Civil de Napoleón, y luego influenció en los ordenamientos jurídicos de Uruguay, Argentina y Brasil.

Latinoamérica ha trasplantado un conjunto de normas e instituciones económicas y jurídicas que buscan promover principios liberales clásicos con el objetivo de fortalecer el Estado de Derecho y la economía de mercado en la región y normas e instituciones para trasformar los sistemas judiciales siguiendo el modelo estadounidense, de igual forma conceptos de filosofía del derecho y teoría política anglosajonas con el fin de construir derecho constitucional.

Así, por ejemplo, según Bonilla (2009, p. 216),

la reforma de la jurisdicción penal en Colombia, es un caso paradigmático del proceso de incorporación del sistema penal acusatorio en los ordenamientos jurídicos latinoamericanos, el gobierno colombiano acordó con el gobierno de los Estados Unidos la importación del sistema penal acusatorio a Colombia para reemplazar al sistema inquisitivo establecido en la Carta de 1991, buscando fortalecer el Estado de Derecho y la administración de justicia, se concretó en el acto legislativo 3 de 2002, en el Código Penal y en el Código de Procedimiento Penal, mediante los cuales se cambió la estructura del proceso penal en el país, buscando una mimesis del sólido sistema jurídico estadounidense, excepto la no incorporación de los juicios con jurados.

Los trasplantes jurídicos, no solamente conllevan a dividir los ordenamientos jurídicos en países desarrollados y subdesarrollados, sino que promueve el pluralismo jurídico, incluyendo más de un sistema jurídico dentro de sus fronteras, también conlleva a todo un sistema a concebir, interpretar, proteger y aplicar el derecho de forma diferente y conforme a sus propias costumbres, reglas, principios y valores.

Uno de los obstáculos de los trasplantes jurídicos, son las diferencias políticas que existen entre los países y pueblos, pues entre mas discrepancias exista en las estructuras del poder político del agente emisor y receptor, menos éxito; evidentemente trasferir normas que nacen en un contexto diferente al que recepciona dicho 
derecho, con características distintas, no permite el progreso del trasplante jurídico, porque hay diferencias notables, y perjudica la identidad y cultura de un Estado.

La ideología de la oralidad viene de otros países y es aplicada en Colombia con el fin de agilizar los procesos judiciales, ello se traduce según la teoría de los trasplantes jurídicos, como una copia que se hizo de un ordenamiento jurídico, a nuestro orden normativo, sin embargo, dicha copia puede ser o no efectiva, eso depende de la forma de aplicación por parte de los operadores jurídicos, del modelo jurídico, entre otros factores, que serán conocidos e investigados en este proyecto.

Se conoce que la escuela judicial Rodrigo Lara Bonilla, para formación de jueces, ha dado capacitaciones en cuanto a la aplicación y uso de la oralidad en los procesos, sin tener buenos resultados en el momento de los litigios, toda vez que algunas de las audiencias revisadas por el grupo de investigación evidencian que los agentes no se adaptan al cambio y persisten en continuar con los expedientes dentro de los procesos o la lectura de documentos elaborados previo a la audiencia.

\section{Balance}

Como balance general de la investigación sobre el tema a estudiar, este punto se estructura de la siguiente manera: primero se hace una revisión de los productos de las investigaciones más importantes realizadas en Colombia durante el período 2002 - 2012 en el que resaltamos el de La Corporación Excelencia En La Justicia, quienes hacen un reporte de los primeros cinco años de funcionamiento del sistema acusatorio en el país y en el que se resaltan los objetivos del acto legislativo 03 de 2002 y su cumplimiento, para concluir que es más eficiente el nuevo sistema en cuanto aumenta la recepción de casos pero sin que ello signifique que se resuelvan en una menor proporción cantidad-tiempo debido a las falencias de las salas de audiencias y de la capacitación del personal. También se denota que la criminalidad grave queda por fuera de la reforma pues la celeridad del proceso lleva a que los delitos menores sean el núcleo duro del proceso y destaca que el sistema, aunque expresa una finalidad netamente garantista, se ha visto trancado por la no identificación de los elementos esencialmente configurativos de lo acusatorio y por la deficiente preparación de los defensores públicos. (Coorporación Excelencia en la Justicia, 2011).

Para observar el desarrollo y existencia de las categorías de análisis propuestas en este trabajo, y resaltando las de oralidad y acusatorio, se partirá de conocimientos 
iniciales socio jurídicos en un trabajo comparativo con la realidad del campo jurídico además del desempeño de los agentes involucrados en las distintas etapas procesales establecidas tras la reforma.

Para este análisis acudiremos a la sociología crítica propia de Boaventura de Sousa Santos (1998), con el fin de explicar el concepto previo de los elementos del Derecho y sus manifestaciones constituyentes de habitus impuestas por los gobiernos.

Considero que son tres los componentes estructurales del derecho: la retórica, la burocracia y la violencia. La retórica no es solo un tipo de conocimiento, sino también una forma de comunicación y una estrategia de toma de decisiones basada en la persuación o convicción mediante la movilización del potencial argumentativo de secuencias y artefactos verbales y no verbales que han sido aceptados. La retórica como un componente estructural del derecho está presente, por ejemplo, en prácticas jurídicas como el acuerdo amistoso de un litigio, la mediacion, la conciliación, la justicia en equidad, etc. La burocracia es una forma de comunicación y una estrategia de toma de decisiones basada en imposiciones autoritarias a través de la movilización del potencial demostrativo de los procedimientos regularizados y los estándares normativos. La burocracia es el componente dominante en el derecho estatal y está presente en las prácticas jurídicas como la adjudicación de casos por los tribunales (juego de suma cero). (Santos, 1998, p.20).

Estos elementos mencionados por Santos son determinantes para la adaptabilidad, pues podría concluirse que el agente se adhiere a la burocracia y no al contrario, por tanto la reforma legislativa 03 de 2002 moldearía los comportamientos de quienes intervienen según lo pretende la burocracia implicita.

Para llegar a concluir si el sistema cumple sus fines al momento de ponerse en marcha, la academia hace investigaciones histórico-comparativas entre los orígenes y la evolución en los distintos países en que se adopta, tal como lo plasma el trabajo de grado Evolución del Sistema Penal Acusatorio en el marco del Derecho Germano, Anglosajón y Colombiano de Over Serrano y David García de la Universidad Colegio Mayor de Cundinamarca.

En segundo lugar, hablaremos de América Latina; en Chile Eduardo Meins Olivares con el artículo El debido proceso en el ordenamiento jurídico chileno y en el nuevo código de procedimiento penal, hace lo propio a partir del estudio 
de una única característica del sistema innovador mediante la comparación de su congruencia con el ordenamiento.

De igual manera se han estudiado casos específicos de entrada en vigor del sistema innovador en países donde se parte de una reforma constitucional, como es el caso del texto El nuevo sistema penal acusatorio en México, un análisis sobre sus alcances y beneficios, de Alejandro Casas Hernández que realizó en la Universidad Michoacana de San Nicolás de Hidalgo durante el 2010, y en el que se hace un estudio sobre el nuevo sistema tras pocos años de su implementación (por supuesto se hace un análisis que parte de lo jurídico.)

Es una meta intrínseca en la búsqueda de soluciones a los conflictos que entraña la cuasi inoperante justicia penal en la que únicamente se punen menos de cinco de cada cien delitos denunciados. No obstante, únicamente puede lograr esos fines a través de una estructura jurídico-judicial conformada integralmente, y tomando en consideración que el derecho evoluciona a la par del conglomerado social. (Biblioteca Universidad Michoacana de San Nicolás de Hidalgo, 2011. 1).

Por último, en el ámbito internacional se han hecho análisis académicos del sistema penal acusatorio y la oralidad bajo los parámetros de adaptabilidad e idoneidad para el contexto en el que se aplica; es decir, evaluar la realidad jurídica del país para hacer los cambios necesarios al momento de introducir el sistema innovador. Por ejemplo, Burgos (2009) en El proceso penal peruano: una investigación sobre su constitucionalidad.

\section{Marco teórico}

Además de lo mencionado en la presentación de esta investigación podemos añadir que el habitus es un sistema de disposiciones duraderas que funcionan como esquemas de clasificación para orientar las valoraciones, las percepciones y las acciones de los sujetos. También constituye un conjunto de estructuras estructuradas y estructurantes, porque implica el proceso mediante el cual los sujetos interiorizan lo social; $y$ funciona como principio generador y estructurador de prácticas culturales y representaciones.

El habitus es concebido por Bourdieu como el principio generador de las prácticas sociales, que permite superar el problema del sujeto individual al constituirse como lugar de incorporación de lo social en el sujeto. 
Las relaciones entre los sujetos históricos situados en el espacio social y las estructuras que los han formado, se objetivan en las prácticas culturales, en la cultura en movimiento que implica la puesta en escena de los habitus, la cultura in-corporada. En este último sentido, el habitus es un conocimiento in-corporado, hecho cuerpo, adherido a los esquemas mentales más profundos, a los dispositivos de la prereflexión, del "inconsciente social”, con los que las personas guían la mayor parte de sus prácticas sin necesidad de racionalizarlas, pero adecuadas a un fin racional.

Este habitus permite relacionar lo objetivo (la posición en la estructura social) y lo subjetivo (la interiorización de ese mundo objetivo). Por ello, el concepto engloba conjuntamente los planos cognitivos, axiológicos y prácticos y cuestiona las distinciones dicotómicas tradicionales entre las categorías lógicas y éticas, por una parte; y el cuerpo y el intelecto, por otra.

Al habitus lo constituyen las estructuras sociales objetivas construidas en dinámicas históricas -los campos-y las estructuras sociales interiorizadas, incorporadas por los individuos en forma de esquemas de percepción, valoración, pensamiento y acción.

Esto no quiere decir que el habitus sea el destino, como se lo interpreta a veces. Siendo producto de la historia, es un sistema abierto de disposiciones que se confrontan permanentemente con experiencias nuevas, y por lo mismo, es afectado también por ellas. Es duradera, pero no inmutable.

En cuanto al elemento acusatorio del sistema de enjuiciamiento penal se presupone una estructura adversarial en donde prima la independencia de las partes intervinientes, la inmediación, la concentración, y ante todo, la imparcialidad del juez. Implica un procedimiento garantista, con igualdad entre el acusado y el defensor. En palabras de Ferrajoli (1995, p. 564),

es el sistema procesal que concibe al juez como un sujeto pasivo, rígidamente separado de las partes y al juicio como una contienda entre iguales iniciada por la acusación, a la que compete la carga de la prueba, enfrentada a la defensa de un juicio contradictorio, oral y público y resuelta por el juez según su libre convicción.

Lo que se busca es esclarecer si el sistema está siendo adoptado a cabalidad o si ha sido adaptado para que los agentes puedan continuar con sus comportamientos clásicos. 
Con el fin de lograr la celeridad y abolir la formalidad intransigente de los procesos que rendían culto al expediente; el artículo 9 de la ley 906 de 2004 determina la obligatoriedad de realizar las actuaciones de forma oral. El sistema innovador trae consigo la oralidad, para que la defensa sea efectiva y la intervención de las partes proceda de manera inmediata ante cada una de las actuaciones procesales que van surgiendo u ocurriendo. La oralidad al ser el medio por el cual las partes expresan su querer, permite que el juez observe los demás aspectos del lenguaje, dándole así una percepción directa de las reacciones, sensaciones que pretende el interviniente.

Para constatar y analizar los conceptos citados esta será una investigacion empírica cualitativa con elementos interdisciplinares entre la sociologia y el derecho; para establecer relaciones enmarcadas en la Teoría del Campo jurídico.

La investigación que se desarrolla tiene un método empírico cuya observación se hará sobre cinco muestras preseleccionadas in situ y cien muestras en video, además de toda la literatura jurídica y las entrevistas de los agentes que participan en el campo, con algunos elementos estadísticos y descriptivos.

\section{Estrategia de investigación}

1. Recopilación de información (consulta de las fuentes primarias y secundarias)

2. Clasificación y selección de documentos. Trayectoria del nuevo sistema con relación al sistema anterior para observar los contrastes temporales en cuanto a sus dinámicas.

3. Análisis de lo investigado.

Para consolidar la información recolectada y determinar los resultados se utilizarán matrices de análisis que seguirán el modelo presentado en la tabla 1 (susceptible de cambios, adiciones, modificaciones o sustracciones). 
Tabla 1. Metodología de la matriz de análisis

\begin{tabular}{|c|c|c|c|c|c|}
\hline \multicolumn{6}{|c|}{ Variables } \\
\hline \multicolumn{3}{|c|}{ Cuantitativas (Estadísticas) } & \multicolumn{3}{|c|}{ Cualitativas } \\
\hline Variables & Indicador & Contenido & Variables & Indicador & Contenidos \\
\hline Tiempo & Semanas & $\begin{array}{l}\text { Duración de } \\
\text { los procesos y } \\
\text { cada etapa. }\end{array}$ & $\begin{array}{l}\text { Comporta- } \\
\text { miento }\end{array}$ & $\begin{array}{l}\text { Resistencia } \\
\text { Ritualización } \\
\text { lenguaje }\end{array}$ & $\begin{array}{l}\text { Alteraciones } \\
\text { Tendencias } \\
\text { Actuación de los } \\
\text { intervinientes. }\end{array}$ \\
\hline MASC & $\begin{array}{l}\text { Principio de } \\
\text { oportunidad. } \\
\text { Preclusión. } \\
\text { Conciliación. } \\
\text { Mediación. }\end{array}$ & $\begin{array}{l}\text { Modo de } \\
\text { terminación } \\
\text { del proceso. }\end{array}$ & Proceso & $\begin{array}{l}\text { Etapas del } \\
\text { Proceso }\end{array}$ & $\begin{array}{l}\text { Cambios en las } \\
\text { etapas procesales. }\end{array}$ \\
\hline Juicio & Juicio oral & $\begin{array}{l}\text { Cuantos pro- } \\
\text { cesos llegan a } \\
\text { juicio oral. }\end{array}$ & $\begin{array}{l}\text { Incidente de } \\
\text { Reparación }\end{array}$ & $\begin{array}{l}\text { Motivaciones } \\
\text { Argumentos }\end{array}$ & $\begin{array}{l}\text { Que motivaciones } \\
\text { llevan a las víctimas } \\
\text { a solicitarlo y con } \\
\text { qué argumentos se } \\
\text { sustenta. }\end{array}$ \\
\hline $\begin{array}{l}\text { Repa- } \\
\text { ración } \\
\text { Integral }\end{array}$ & Cantidad & $\begin{array}{l}\text { Número de } \\
\text { procesos que } \\
\text { acuden a la } \\
\text { reparación } \\
\text { y cuantos se } \\
\text { reparan. }\end{array}$ & Intermediarios & $\begin{array}{l}\text { Funciones. } \\
\text { Actuaciones. }\end{array}$ & $\begin{array}{l}\text { ¿Cómo actúa cada } \\
\text { intermediario } \\
\text { durante el proceso? } \\
\text { Cambios de las } \\
\text { funciones entre } \\
\text { sistemas. }\end{array}$ \\
\hline $\begin{array}{l}\text { Errores } \\
\text { del } \\
\text { sistema }\end{array}$ & $\begin{array}{l}\text { Cifras de } \\
\text { condenados } \\
\text { por errores } \\
\text { judiciales. }\end{array}$ & $\begin{array}{l}\text { Errores } \\
\text { procesales } \\
\text { que llevan } \\
\text { a condenar } \\
\text { inocentes. }\end{array}$ & Tecnología & $\begin{array}{l}\text { Grabaciones } \\
\text { Audio } \\
\text { Salas aptas. } \\
\text { Ciencias } \\
\text { forenses. }\end{array}$ & $\begin{array}{l}\text { Uso de la tecnolo- } \\
\text { gía en los procesos } \\
\text { y pruebas. }\end{array}$ \\
\hline \multirow[t]{2}{*}{$\begin{array}{l}\text { Con- } \\
\text { gestión } \\
\text { carcelaria }\end{array}$} & $\begin{array}{l}\text { Presos } \\
\text { anuales }\end{array}$ & $\begin{array}{l}\text { Cuantos } \\
\text { procesos } \\
\text { terminan con } \\
\text { pena privativa } \\
\text { de la libertad. }\end{array}$ & $\begin{array}{l}\text { Interdiscipli- } \\
\text { nariedad }\end{array}$ & $\begin{array}{l}\text { Disciplinas } \\
\text { Implicaciones } \\
\text { Perspectivas }\end{array}$ & $\begin{array}{l}\text { Vinculación de } \\
\text { otras disciplinas } \\
\text { durante el proceso, } \\
\text { importancia de } \\
\text { estas. }\end{array}$ \\
\hline & & & Oralidad & $\begin{array}{l}\text { Importancia } \\
\text { Celeridad } \\
\text { Derecho } \\
\text { Comparado }\end{array}$ & $\begin{array}{l}\text { Manejo de la } \\
\text { oralidad en el } \\
\text { proceso acusatorio } \\
\text { y comparación } \\
\text { con otras áreas del } \\
\text { derecho. }\end{array}$ \\
\hline
\end{tabular}

Fuente: Elaboración propia. 


\section{Conclusiones}

Acerca de la tesis central podemos concluir que es vigente hasta que la investigación la reitere o la niegue, pero que de acuerdo con su planteamiento es necesario trascender la reforma normativa hasta llegar a los dispositivos interiorizados de los operadores del derecho o habitus jurídicos, identificarlos en la tensión que en las prácticas jurídicas puedan presentar entre los valores culturales arraigados en los tradicionales y las paradigmáticas formas de enjuiciamiento inquisitivo frente a las nuevas formas adversariales del sistema en vigencia.

Se puede concluir sobre la primera parte, con base en los antecedentes históricos del Sistema Oral Penal Acusatorio y citando a Tocqueville (1996), que a través de las costumbres y las prácticas sociales se construyen un habitus colectivo y un Ethos que fundamentan la vida cotidiana, sus normas, reglas y conductas traducidas desde entonces en sus sistemas jurídicos a lo largo de su historia. Estas razones suscitan el interrogante de ¿Cómo un sistema como el penal oral acusatorio proveniente de Norteamérica se puede adaptar o ajustar en sociedades como la nuestra cuyas estructuras sociales se basan en habitus y valores tan diferentes y tan vulnerables?

De la segunda parte Móviles del sistema en Colombia y su importación. Se concluye en cuanto a lo político que cuando se habla del Sistema Oral Penal Acusatorio", se piensa en primer lugar en el marco neoliberal hasta ahora señalado en donde surge y los móviles políticos y económicos del mismo. Cuya tendencia se puede señalar en varios países de América Latina. Posiblemente con objetivos tales como la simplificación del tiempo en los procesos, ahorro económico en la inversión de los mismos por parte de los Estados y simplificación de las infraestructuras entre otros principios próximos al utilitarismo y pragmatismos anglosajón, con el agregado de que la racionalidad y la planificación del sistema asegurarían más pecunio, para que estos cumplan con sus compromisos adquiridos en los empréstitos y el mundo de los mercados fluyan con el nuevo laissez paseé y laissez faire empujados por la mano invisible del egoísmo y la competencia pura.

De lo jurídico como móvil se concluye que los objetivos más importantes que motivaron la reforma fueron el de hacer más eficiente el sistema penal; perseguir la criminalidad grave y organizada, según lo político criminal vigente; hacer más garantista el sistema penal; garantizar idónea atención a víctimas, implementar el programa e justicia restaurativa; mejorar la confianza en el sistema penal y mejorar 
la calidad de las decisiones en materia penal. Pero que de acuerdo al balance hasta hoy, los resultados han sido muy débiles en cuanto sus objetivos.

Y por último, sobre la tercera parte, se puede concluir que con base en la investigación argumentada en las teorías del campo y del habitus, tal vez se puedan lograr indicadores que determinen la tendencia que tiene esta experiencia del sistema en cuanto su adaptación o aplicación en Colombia.

\section{Referencias}

Bonilla Daniel. (2009). Teoría del Derecho y Trasplantes Jurídicos. Universidad de los Andes. 1a edición. Bogotá. pp. 216.

Burgos, V. (2009). El proceso penal peruano: una investigación sobre su constitucionalidad. Recuperado de: http://sisbib.unmsm.edu.pe/bibvirtual/tesis/human/burgos_m_v/ indice_burgos.htm

Carrillo, F. (1991). Fiscalía General y sistema acusatorio. Gaceta constitucional (68). Bogotá. Corporación Excelencia en la Justicia. (2011). Balance de los primeros cinco años de funcionamiento del Sistema Penal Acusatorio en Colombia. Kimpres Ltda. Bogotá.

Flórez, J. (2010). La Sociología del Derecho, un primer encuentro con la interdisciplinariedad. Recuperado en: http://iuspoliticum.blogspot.com/2010/02/sobre-la-naturalezaparasitaria-del.html

Londoño, H. (1991). Propuesta de estructura del sistema penal acusatorio. Proyecto acto de la reforma de la constitución No 11; Asamblea Nacional Constituyente, Gaceta constitucional (10). Recuperado en: http://www.elabedul.net/Documentos/Temas/ Asamblea_Constituyente/Gacetas/Gacetas_1-50/gaceta_010.php

Meins, E. (1999). El debido proceso en el ordenamiento jurídico chileno y en el nuevo código de procedimiento. Ius et Praxis, vol. 5, núm. 1, pp. 445-460, Universidad de Talca. Chile. Recuperado en: http://www.redalyc.org/articulo.oa?id=19750117>

Morales, H., Martínez f. (2011). Oralidad en el sistema acusatorio y sustentación de la apelación contra la sentencia en la Ley 1395 de 2010. Tesis de especialización en procedimiento penal constitucional y justicia militar. Universidad Militar Nueva Granada. Bogotá. Recuperado en: http://repository.unimilitar.edu.co/bitstream/10654/3662/2/MoralesBarbosaHectorAlonso2011.pdf

Moreno, A., Ramírez, J. (2011). Sociología del campo jurídico en Colombia, Relaciones y Perspectivas. Bogotá: Ediciones USTA:

Moreno, H., Fortich, M. (2013). El Campo Jurídico en América Latina y su autonomía (1990-2010). Universidad Libre. Bogotá. 
Santos, B. (1998). La globalización del derecho. Los nuevos caminos de la emancipación. ILSA. Universidad Nacional de Colombia.

Serrano, O., García, D. (2008). Evolución del Sistema Penal Acusatorio en el marco del Derecho Germano, Anglosajón y Colombiano. Recuperado en: http://www.unicol mayor.edu.co/revistajuridica/pdf/primera\%20edicion/evolucion\%20del\%20sistema.pdf Tocqueville, A. (1996). La Democracia en América. Fondo de Cultura Económica. México. 